\title{
Testing and Analysis of Aluconcrete Beams
}

\author{
R. J. Bridle'; T. M. Roberts'; N. Uran³; and A. K. A. Razak
}

\begin{abstract}
A series of four-point bending, quasi-static and high-cycle fatigue tests has been conducted on aluconcrete beams consisting of an aluminum extrusion acting compositely with a high-strength concrete infill. Observations and analysis of the quasi-static tests and test results indicate that fully effective composite action was maintained up to failure, with negligible or minimal slip occurring between the aluminum extrusion and high-strength concrete. Failure of the beams during the high-cycle fatigue tests resulted from a gradual degradation of the bond between the concrete and aluminum, resulting in noticeable slip and a corresponding reduction in composite action. Even so, the fatigue test beams, which had a shear bond transmission length of only $575 \mathrm{~mm}$, were able to sustain approximately one-quarter of a million load cycles from approximately 5 to $50 \%$ of their ultimate load.
\end{abstract}

DOI: 10.1061/(ASCE)0899-1561(2007)19:6(523)

CE Database subject headings: Concrete; Composite construction; Bending; Fatigue; Beams.

\section{Introduction}

A preliminary experimental and theoretical investigation of aluconcrete beams, consisting of an aluminum extrusion acting compositely with a high-strength concrete infill, is described. Aluminum alloys possess excellent corrosion resistance in most environments but it is a widely held view that they suffer serious corrosion when in contact with cement-based materials. For this reason British Standard 8118 (BSI 1991) recommends that aluminum alloys are provided with a coating of bituminous paint to prevent contact with such materials. However, according to Goddard et al. (1967), many aluminum alloys, in particular the 6000 series, are not seriously corroded by long term embedment in cement based materials, unless there is frequent intermittent wetting and drying. It is believed that the initial reaction between aluminum and wet concrete is largely responsible for generating the effective bond between the aluminum and concrete observed in the present series of tests.

\section{Experimental Investigation}

\section{Test Specimens and Materials}

Four 3,000 mm long aluconcrete beam specimens were manufactured from a $6082 \mathrm{~T} 6(\mathrm{Al}+\mathrm{Mg}+\mathrm{Si})$ aluminum alloy extrusion and

\footnotetext{
${ }^{1}$ Honorary Professor, School of Engineering, Cardiff Univ., Cardiff CF24 3AA, Wales, U.K.

${ }^{2}$ Professor, School of Engineering, Cardiff Univ., Cardiff CF24 3AA, Wales, U.K. E-mail: RobertsTM@cf.ac.uk

${ }^{3}$ Postgraduate Student, School of Engineering, Cardiff Univ., Cardiff CF24 3AA, Wales, U.K.

${ }^{4}$ Lecturer, Faculty of Engineering, Univ. of Malaysia Sarawak (UNIMAS), 94300 Kota Samaraham, Sarawak, Malaysia.

Note. Associate Editor: Roberto Lopez-Anido. Discussion open until November 1, 2007. Separate discussions must be submitted for individual papers. To extend the closing date by one month, a written request must be filed with the ASCE Managing Editor. The manuscript for this technical note was submitted for review and possible publication on May 6, 2005; approved on August 15, 2006. This technical note is part of the Journal of Materials in Civil Engineering, Vol. 19, No. 6, June 1, 2007. (C)ASCE, ISSN 0899-1561/2007/6-523-525/\$25.00.
}

high-strength concrete. Two of the beams had the cross-section dimensions shown in Fig. 1(a), whereas the remaining two beams had the cross-section dimensions shown in Fig. 1(b).

The following properties of the aluminum extrusion were determined in accordance with BS 18 (1970): Yield stress (0.2\% proof) $f_{a y}=289 \mathrm{~N} / \mathrm{mm}^{2}$; ultimate stress $f_{a u}=312 \mathrm{~N} / \mathrm{mm}^{2}$, and elastic modulus $E_{a}=64,400 \mathrm{~N} / \mathrm{mm}^{2}$.

The high-strength concrete was manufactured with a target cube compressive strength of $100 \mathrm{~N} / \mathrm{mm}^{2}$ (Taylor et al. 1996). The following properties were determined in accordance with BS 1881 (1983) and a cylinder torsion test developed by Norris et al. (1990): Compressive strength $f_{c u}=112 \mathrm{~N} / \mathrm{mm}^{2}$ (cube test); tensile strength $f_{c t}=7.53 \mathrm{~N} / \mathrm{mm}^{2}$ (split cylinder test); tensile strength $f_{c t}=8.62 \mathrm{~N} / \mathrm{mm}^{2}$ (torsion test); and elastic modulus $E_{c}=41,500 \mathrm{~N} / \mathrm{mm}^{2}$ (torsion test).

\section{Quasi-Static Tests}

Two 2,000 $\mathrm{mm}$ lengths of the aluminum extrusion and the four $3,000 \mathrm{~mm}$ long aluconcrete beams were subjected to quasi-static four-point bending tests as illustrated in Figs. 2(a and b). One length of aluminum extrusion and one of each pair of aluconcrete beams were subjected to sagging $(S)$ moments (extreme fibers of aluminum webs and exposed surface of concrete in compression), whereas the other length of aluminum extrusion and the remaining two aluconcrete beams were inverted and subjected to hogging $(H)$ moments.

After the initial tests on the four $3,000 \mathrm{~mm}$ long aluconcrete beams the central damaged region was removed to produce eight $1,350 \mathrm{~mm}$ long aluconcrete beams. Four of these beams were also subjected to quasi-static four-point bending tests (sagging and hogging), as shown in Fig. 2(c), whereas the remaining four beams were subjected to high-cycle fatigue tests under similar loading conditions.

The initial tests on the aluminum extrusion and 3,000 mm aluconcrete beams were conducted approximately 60 days after casting. The tests on the $1,350 \mathrm{~mm}$ long aluconcrete beams were conducted approximately 1 year later, after storing the beams under laboratory dry conditions. Tests on nominally identical aluconcrete beams of significantly different length provided an indication of the effectiveness of the bond between the aluminum 